spheres are designed to encourage the formation and adherence of a neointimal biological lining. The neointima then functions as the permanent biocompatible surface. ${ }^{18}$ For long term implantation this biological lining may be further manipulated. ${ }^{19}$

Implantable left ventricular assist systems with an external power cable are used now as bridging devices before transplantation. ${ }^{20}$ For permanent implantation the electronic controller will be implanted in the patient together with the device and the drive unit.

Extensive long term reliability tests of these complete systems are being conducted together with studies of implantation in animals. Four American companies are evaluating the various models. ${ }^{5}$ The first implant of a fully implantable permanent ventricular assist system is planned within the next two years.

The cost of developing and using these permanent implantable mechanical devices should be compared with the cost of maintaining patients with end stage heart failure-over $\$ 11$ billion yearly in the United States. ${ }^{21}$ It has been estimated that 30000 implantable systems would cost $\$ 3$ billion. ${ }^{21}$ This would not all be extra costs as money would be saved on the medical treatment that would no longer be required. Hardware costs should also fall as demand increases. As these devices should improve survival rates and the quality of life this expenditure would be reasonable.

At present pneumatic total artificial hearts should be used only as bridging devices before transplantation. Total artificial hearts will eventually be required for patients with biventric:'ar failure, and electric total artificial hearts being developed may overcome the disadvantages encountered with long term use of the pneumatic total artificial heart. In the mean time, the development of left ventricular assist systems seems to be a better option for permanent implantation in recipients who are unacceptable as candidates for transplantation.

T R GRAHAM Research Fellow C T LEWIS

Consultant Cardiothoracic Surgeon

Department of Cardiothoracic Surgery,

The London Hospital, London E1 1BB

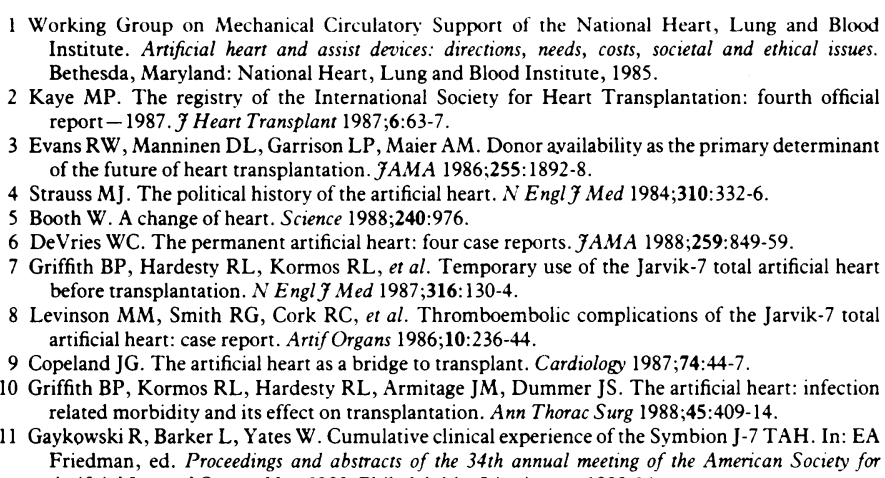

1 Working Group on Mechanical Circulatory Support of the National Heart, Lung and Bloo Institute. Artificial heart and assist devices: directions, needs, costs, societal and ethical issues. Bethesda, Maryland: National Heart, Lung and Blood Institute, 1985.

2 Kaye MP. The registry of the International Society for Heart Transplantation: fourth official report - 1987. F Heart Transplant 1987;6:63-7.

3 Evans RW, Manninen DL, Garrison LP, Maier AM. Donor availability as the primary determinant of the future of heart transplantation. FAMA 1986;255:1892-8.

4 Strauss MJ. The political history of the artificial heart. N Engl f Med 1984;310:332-6.

5 Booth W. A change of heart. Science 1988;240:976.

6 DeVries WC. The permanent artificial heart: four case reports. FAMA 1988;259:849-59.

7 Griffith BP, Hardesty RL, Kormos RL, et al. Temporary use of the Jarvik-7 total artificial heart before transplantation. N Engl F Med 1987;316:130-4.

8 Levinson MM, Smith RG, Cork RC, et al. Thromboembolic complications of the Jarvik-7 total artificial heart: case report. Artif Organs 1986;10:236-44.

9 Copeland JG. The artificial heart as a bridge to transplant. Cardiology 1987;74:44-7.

10 Griffith BP, Kormos RL, Hardesty RL, Armitage JM, Dummer JS. The artificial heart: infection related morbidity and its effect on transplantation. Ann Thorac Surg 1988;45:409-14.

11 Gaykowski R, Barker L, Yates W. Cumulative clinical experience of the Symbion J-7 TAH. In: EA Friedman, ed. Proceedings and abstracts of the 34th annual meeting of the American Society for Artificial Internal Organs May 1988. Philadelphia: Lippincott, 1988:14.
12 Farrar DJ, Hill JD. Heterotopic prosthetic ventricle as a bridge to cardiac transplant. $N$ Engl f Med 1988;319:311.

13 Kanter KR, McBride LR, Pennington DG, et al. Bridging to cardiac transplantation with pulsatile ventricular assist devices. Ann Thorac Surg 1988;46:134-40.

14 Farrar DJ, Hill JD, Gray JR, et al. Heterotopic prosthetic ventricles as a bridge to cardiac transplantation. $N$ Engl f Med 1988;318:333-40.

15 Pierce WS. Artificial hearts and blood pumps in the treatment of profound heart failure. Circulation 1983;68:883-8.

16 Olsen DB, Unger F, Oster $\mathrm{H}$, et al. Thrombus generation within the artificial heart. 7 Thorac Cardiovasc Surg 1975; 70:248-55.

17 Clark R, Boyd J, Moran J. New principles governing the tissue reactivity of prosthetic materials. f Surg Res 1974;16:510-22.

18 Dasse KA, Chipman SD, Sherman CN, Levine AH, Frazier OH. Clinical experience with textured blood contacting surfaces in ventricular assist devices. ASAIO Trans 1987;33:418-25.

19 Graham TR, Chalmers JAC, Syndercombe-Court D, et al. Initial experience with seeding of neointima in a rough surface left ventricular assist device. Artif Organs 1987;11:318-9.

20 Starnes VA, Oyer PE, Portner PM, et al. Isolated left ventricular assist as bridge to cardiac transplantation. I Thorac Cardiovasc Surg 1988;96:62-71.

21 Poirier V. The economic burden of artificial hearts. In: Nose Y, Kjellstrand C, Ivanovich P, eds. Progress in artificial organs 1985. Cleveland: ISAO Press, 1986:96-9.

\title{
Checking on those who care for children
}

\author{
For some jobs checks must be run for a criminal background
}

The Department of Health has recently produced a circular recommending that health authorities should check with the police for a history of relevant criminal offences before appointing staff who will have "substantial access to children." Substantial access means those who care all day for children who are inpatients - that is, most paediatric nurses. The recommendations come from a working party appointed after a children's voluntary worker with a criminal background had murdered a child. The checks must be supported, but they will raise substantial difficulties and will not necessarily prevent child molesters from gaining access to children through health work. The circular deals with many practical points:

- Who should be nominated as the "senior nominated officer" to collect the information? In a district health authority the obvious possibilities are the senior personnel officer or a senior member in the occupational health service

- The information should be collected only when a job offer is being considered - that is, not when an applicant is being short listed.
- The applicant should be told that such a check is being made

- The senior nominated officer should treat information received appropriately and destroy it afterwards

- The police are indemnified against prosecution

- The employing authorities should consider giving some employers - for instance, agency staff - a letter valid for one year that shows that a check has been made

- Existing staff should be checked only if they move to a new position offering substantial access to children or if allegations are made.

The biggest drawback to this way of protecting children is time: it may take up to three months for such a check to be processed. This delay will have serious consequences if staff are needed urgently. The second problem is that the process may not be effective. It will protect authorities from looking foolish in appointing someone who has a previous conviction for child molesting to work with children. But probably fewer than $1 \%$ of child molesters are charged with offences, many 
fewer found guilty. These checks may thus give rise to a false sense of security and diminish vigilance and supervision. All organisations therefore need careful guidelines governing access to children.

There are also legal problems. As the police cannot be indemnified for incorrect information the employing bodies may be liable for mistakes - if, for instance, the wrong John Smith is checked. Finally, there is the difficulty of interpreting the information received and its relevance to the job in question. For example, the gay movement points out that a conviction for a homosexual offence with, say, a 20 year old is not equivalent to child abuse, and many offences uncovered will have nothing to do with children and may date back many years. The nominated officer may need expert advice in assessing information received.

An attempt to select out those with a relevant criminal background must, however, be made, and if we can bar even one of the multiple child sex offenders much will have been achieved.

J C STURGE

Consultant Child and Adolescent Psychiatrist,

Paediatric Department,

Northwick Park Hospital,

Middlesex HAl 2UJ

\title{
Tetrahydroaminoacridine (THA) in Alzheimer's disease
}

\author{
Not ready for routine use
}

It must be unique for newspaper headlines describing a new treatment for Alzheimer's disease to be based on reports from a sufferer who claims to have been successfully treated - and a Nobel prizewinning scientist at that. ${ }^{\prime}$ The drug in this case was the anticholinesterase tetrahydroaminoacridine. The sufferer was one in a series of 35 patients, ${ }^{2}$ details of whom are not yet published, but the researcher in charge of the study was said in the Sunday Times to regard the results as "staggering." The scientist-patient claims that the drug allowed him to be active and creative again after a period of failing memory and long inactivity.

There are good reasons why manipulating the cholinergic system might be effective in treating Alzheimer's disease. A deficit in the cholinergic system in the disease was first described by Davies and Moloney in 1976 and is now well established. ${ }^{3}$ The deficit correlates both with the severity of dementia ${ }^{+}$and with measures of the main histological hallmarks of the disease-senile plaques and neurofibrillary tangles. ${ }^{5}$ Other neurotransmitter systems are also deficient in Alzheimer's disease: neurochemical analysis of brain tissue at necropsy has suggested that somatostatin ${ }^{6}$ and serotonin ${ }^{7}$ are deficient, and other studies have implicated deficiencies in dopamine ${ }^{8}$ glutamate, ${ }^{9}$ and aminobutyric acid. ${ }^{10}$ Neurochemical analysis of biopsy material from patients with Alzheimer's disease has confirmed the cholinergic and serotonergic deficits but not the other deficits. ${ }^{11}$

The successful treatment of Parkinson's disease, another degenerative disorder, with a drug designed to correct a neurotransmitter deficiency has raised hopes that drugs that enhance the cholinergic system would be beneficial in Alzheimer's disease. The early results of such intervention showed that whichever part of the cholinergic system was modified precursor anticholinesterase or receptor agonists were largely unsuccessful. ${ }^{12}{ }^{13}$ Later and more rigorous studies described a modest improvement, especially in older patients with the more "benign" form of Alzheimer's disease ${ }^{1+}$ who were treated with lecithin ${ }^{15}$ and in some patients treated with physostigmine. ${ }^{16}$ Trials of receptor agonists RS86, oxotremarine, bethanecol, and arecoline have shown no clinical benefits. ${ }^{17-20}$

Tetrahydroaminoacridine is a potent centrally acting anticholinesterase and cerebral stimulant ${ }^{21}$ that has several other postulated actions: selective blockade of potassium channels in the central nervous system (possibly because of its structural similarity to 4-aminopyridine ${ }^{22}$ ), down regulation of $M_{1}$ receptors, ${ }^{23}$ alteration in phosphorylation, ${ }^{2+}$ and at high dosage presynaptic and postsynaptic blockade of both muscarinic and nicotinic receptors. ${ }^{24}$ Anticholinesterases increase the need for free choline, ${ }^{25}$ which may explain why in some of the few trials of tetrahydroaminoacridine it has been used with lecithin.

Despite some rationale for its use in Alzheimer's disease it is difficult to see why tetrahydroaminoacridine should be more effective than any other cholinomimetic agent. Kaye et al reported only a modest benefit from combined tetrahydroaminoacridine and lecithin (and no benefit from tetrahydroaminoacridine alone), ${ }^{26}$ and two reports by Summers et al in 1981 and 1986 are the only reports of appreciable clinical benefit. ${ }^{27}{ }^{28}$ These reports have been criticised on several counts: lack of clarity in the inclusion and exclusion criteria, no separate analysis of the blind tetrahydroaminoacridine trial versus the blind placebo trial, the dubious validity of the outcome criteria, no explanation of the apparent absence of a placebo effect, and because the subjects were concomitantly taking lecithin. ${ }^{29-33}$ The trials have, however, stimulated more critical examination of the efficacy of the drug. Gauthier et al in a double blind study of tetrahydroaminoacridine and lecithin reported a modest but appreciable improvement in both functional ability and cognition over eight weeks ${ }^{34}$ but also a high incidence of clinically important side effects, with autonomic symptoms in four fifths of their 51 patients, and hepatotoxicity (based on abnormal results with liver function tests but no biopsy examination) in a third. These side effects were said to be reversible with adjustment of the dose of tetrahydroaminoacridine. The large multicentre trial in the United States ${ }^{35}$ was discontinued because of the high incidence of hepatotoxicity ${ }^{36}$ but has subsequently resumed.

How serious are the unwanted effects of tetrahydroaminoacridine? Troublesome and occasionally serious cholinergic side effects, including disturbances of the gastrointestinal tract and hypotension, ${ }^{37}$ occur at doses lower than those used by Summers et al. ${ }^{27}{ }^{28}$ These are reported to be reversible when the dose is titrated. But hepatotoxicity is much more serious and occurs in a fifth to a third of patients; it seems to take the form of an autoimmune granulomatous hepatitis, ${ }^{38}$ which is said to be reversible on stopping the drug, but so far few follow up results have been reported.

The story of tetrahydroaminoacridine is a good illustration of the dilemma that faces doctors attempting to treat a devastating degenerative condition: the pressure to do something versus the maxim of "above all do no harm." 35 If tetrahydroaminoacridine is eventuilly proved to have worthwhile clinical benefits and when there are reliable data 